2012-05-01

\title{
Activation of phonological and semantic codes in toddlers
}

\author{
Mani, N
}

http://hdl.handle.net/10026.1/9952

10.1016/j.jml.2012.03.003

JOURNAL OF MEMORY AND LANGUAGE

Elsevier BV

All content in PEARL is protected by copyright law. Author manuscripts are made available in accordance with publisher policies. Please cite only the published version using the details provided on the item record or document. In the absence of an open licence (e.g. Creative Commons), permissions for further reuse of content should be sought from the publisher or author. 


\title{
Activation of phonological and semantic codes in toddlers
}

\author{
Nivedita Mani ${ }^{\mathrm{a}, *}$, Samantha Durrant ${ }^{\mathrm{b}}$, Caroline Floccia ${ }^{\mathrm{b}}$ \\ a "Language Acquisition" Junior Research Group, Georg-August-Universität Göttingen, Germany \\ ${ }^{\mathrm{b}}$ School of Psychology, University of Plymouth, United Kingdom
}

\section{A R T I C L E I N F O}

\section{Article history:}

Received 17 February 2011

revision received 6 March 2012

Available online 7 May 2012

\section{Keywords:}

Phonological priming

Word recognition

Phono-semantic priming

Toddlers

\begin{abstract}
A B S T R A C T
What are the processes underlying word recognition in the toddler lexicon? Work with adults suggests that, by 5 -years of age, hearing a word leads to cascaded activation of other phonologically, semantically and phono-semantically related words (Huang \& Snedeker, 2010; Marslen-Wilson \& Zwitserlood, 1989). Given substantial differences in children's sensitivity to phonological and semantic relationships between words in the first few years of life (Arias-Trejo \& Plunkett, 2010; Newman, Samuelson, \& Gupta, 2009; Storkel \& Hoover, 2012), the current set of experiments investigated whether children younger than five also show such phono-semantic priming. Using a picture-priming task, Experiments 1 and 2 presented 2-year-olds with phono-semantically related prime-target pairs, where the label for the prime image is phonologically related (Experiment 1 - onset CV overlap, Experiment 2 - rhyme VC overlap) to a semantic associate of the target label. Across both experiments, toddlers recognised a word faster when this was preceded by a phonosemantically related prime relative to an unrelated prime. Overall, the results provide strong evidence that word recognition involves cascaded processing of phono-semantically related words by 2-years of age.
\end{abstract}

(c) 2012 Elsevier Inc. All rights reserved.

\section{Introduction}

What are the mental representations activated during our processing of the written word cat, a picture of a cat, or the sound/kæt/? Evidence suggests that these orthographic, visual and auditory representations co-activate one another, such that seeing a picture of a cat may lead to our internal generation of the word cat (Jescheniak \& Levelt, 1994; Mani \& Plunkett, 2010; Meyer, Belke, Telling, \& Humphreys, 2007), or to our consideration of the semantic features associated with cats, such as 'animal', 'four-legged', and 'furry' (e.g., Huettig \& McQueen, 2007). Adults are faster at recognising a word like clock, when primed by either semantically related words (e.g., watch, Meyer \& Schvaneveldt, 1971) or phonologically related words (e.g., sock, Goldinger, Luce, \& Pisoni, 1989; Marslen-Wilson

\footnotetext{
* Corresponding author. Address: "Language Acquisition” Junior Research Group, Georg-August-Universität Göttingen, Goßlerstraße 14, 37073 Göttingen, Germany. Fax: +495513910889.

E-mail address: nmani@gwdg.de (N. Mani).
}

\& Zwitserlood, 1989; Slowiaczek \& Hamburger, 1992; Slowiaczek, Nusbaum, \& Pisoni, 1987). These results, among many others, suggest that word recognition involves the additional processing of other words phonologically or semantically related to the word to be recognised.

Furthermore, work with adults (Huettig \& McQueen, 2007; Marslen-Wilson \& Zwitserlood, 1989; Yee \& Sedivy, 2006) is consistent with the cascaded activation of multiple codes (e.g., phonological, semantic and visual) during the processing of words, pictures or sounds. For instance, Marslen-Wilson and Zwitserlood provide evidence for the activation of phono-semantically related words during word recognition. As in previous studies on semantic priming (Meyer \& Schvaneveldt, 1971), recognition of a Dutch word bij (bee) was facilitated when primed by a semantically related word like honing (honey). In addition, recognition of $b i j$ was also facilitated when primed by a non-word phonologically similar to a semantic associate of bij (woning). The influence of woning on subjects' recognition of bij was explained by suggesting that woning activated the 
phonological codes of words related to woning i.e., honing, and its semantic associates, i.e., through honing, bij. Similarly, Yee and Sedivy (2006) found that adults looked at a picture of a key upon hearing the word log, due to the activation of the onset-overlapping word, lock and its semantic correlate, key. Thus, word recognition in adults involves processing of not just those words phonologically and semantically related to the target word for recognition, but also additional cascaded processing of other words phonologically and semantically related to these related words.

Some recent work illuminates the time-course of activation of multiple codes (phonological, semantic and visual) in priming tasks (Huettig \& McQueen, 2007). Huettig and McQueen provide evidence for cascaded flow of activation from the phonological (i.e., subject looks at a phonological competitor) to the semantic and visual levels of processing (looks to a semantic competitor or a visual competitor). Although such cascaded activation of phonological, semantic and visual codes appears dependent on the specifics of the task presented to subjects, (e.g., the ISI between prime and target, the modality of the prime) their work suggests that the activation of phonological codes precedes the activation of semantic and visual codes in speech processing.

Similarly, using a task similar to Yee and Sedivy (2006), Huang and Snedeker (2010) report evidence of phonosemantic priming in 5-year-olds, i.e., children looked at a picture of a key upon hearing the word $\log$, due to phonological activation of the phonologically related word lock and its semantic associate, key. Thus, by at least 5 -years of age, children, like adults, are sensitive to phono-semantic priming. What, then, is the developmental time-course of such multiple code activation, i.e., when do children begin to display phono-semantic priming effects as reported by Yee and Sedivy (2006) and do children younger than 5years of age also show such effects?

Recent research suggests considerable developmental differences in children's sensitivity to the phonological or semantic organisation of words even in the first few years of life. For instance, one prominent view in the developmental literature suggests that young children possess holistic representations of words such that these words are not represented in full segmental detail (Charles-Luce \& Luce, 1990; Metsala \& Walley, 1998). If, as is suggested, orthographical acquisition changes the way words are phonologically represented in the mental lexicon (Huettig, Singh, \& Mishra, 2011; Ziegler \& Goswami, 2005), pre-literate children may not show phonologically mediated priming effects to the same extent as older children or adults.

Furthermore, even if young children pay attention to the segmental (Swingley \& Aslin, 2000, 2002) and sub-segmental content of words (Mani \& Plunkett, 2010; White \& Morgan, 2008), a number of studies report an influence of increasing vocabulary size on children's sensitivity to the frequency with which phonemes cluster together in word-like units (Coady \& Aslin, 2004; Storkel \& Hoover, 2012). For instance, Coady and Aslin (2004) show that between $2 ; 5$ and 3;5 years of age, children show increasing sensitivity to the frequency of diphone units in their lan- guage. Thus, 3;5-year-olds, but not 2;5-year-olds, were more accurate in repeating of non-words consistent with high diphone probabilities in their language than other non-words. Similarly, Storkel and Hoover (2012) find that, between 2 to 6 years, children's sensitivity to part-word probability in a word learning task was influenced by their expressive vocabulary size - children with the lowest expressive vocabulary scores showed no effects of probability distribution of vowel-consonant clusters in their language, while children with high vocabulary scores learnt words with low diphone probability ratings better than words with high diphone probability ratings. Thus, the influence that phonologically similar words have on each other is strongly correlated with the size of a child's lexicon, and consequently, the age of the child.

Similarly, a comparison of research examining the ease of children's word learning shows considerable vulnerability of neighbourhood effects at around 2 years of age. Thus, Swingley and Aslin (2007) find that 18-month-olds found it harder to learn words that sound similar to a word already in the child's lexicon (e.g., tog that sounds similar to dog), while Newman et al. (2009) (akin to Storkel \& Hoover, 2012) report differences in children's learning of a word like wat (with many neighbours such as cat, rat, mat, and fat) between 20- and 24-months of age. Newman et al. (2009) report that only 24-month-olds, and not 20month-olds, showed significant neighbourhood effects in a word learning task, although combining both age-groups, children who knew more neighbours for a word were more likely to learn the word than children who knew fewer neighbours for the same word.

Phonological priming studies with children also reflect changes in the influence that words have on one another between 18- to 24-months of age. For instance, Mani and Plunkett (2011) find that, when primed by an image of a name-known object (e.g., ball), 24-month-olds looked less at a target image whose label was similar to the label for the prime object (e.g., book) relative to an image whose label was phonologically unrelated to the prime. Mani and Plunkett (2011) interpret this effect as evidence for interference caused by co-activation of other words that sound similar to the prime and target labels. In contrast, Mani and Plunkett (2010) found that 18month-olds showed facilitation in word recognition when primed by a phonologically related word. Thus, 18-month-olds looked more at a target image (e.g., book) whose label was similar to the label for the prime object (e.g., ball) relative to an image whose label was phonologically unrelated to the prime. The authors explain this difference between the age-groups on the basis of the rapidly expanding vocabulary of children between 18- and 24-months of age - once children acquire a sufficient mass of items that sound similar to each other in their lexicon, these words begin to interfere with each other during processing such that processing of ball involves consideration of words sounding similar to ball, e.g., doll, bin, boat (Neighbourhood activation model, Luce \& Pisoni, 1998 or Cohort Model, Marslen-Wilson \& Welsh, 1978; Marslen-Wilson \& Zwitserlood, 1989; TRACE model: McClelland \& Elman, 1986). These words create a competitive atmosphere in which the target word, 
i.e., book, needs to be recognised, leading to reduced recognition of book in primed trials. Prior to this, at 18-months of age, however, there appears to be a reduced effect of similar sounding words on word recognition (Mani \& Plunkett, 2011) and word learning (Newman et al., 2009), perhaps due to the fact that there are fewer words in the 18-month-old lexicon to interfere with target recognition.

Similarly, semantic priming studies also report considerable changes towards the end of the second year of life, with 18-month-olds not showing any influence of a taxonomically and associatively related prime on children's responding in contrast to 21-month-olds (Arias-Trejo \& Plunkett, 2010) and 24-month-olds (Styles \& Plunkett, 2011; Torkildsen et al., 2006). More recent work further suggests that even 21-month-olds do not display a priming effect when the prime is either taxonomically or associatively related to the target, whilst 24-month-olds do (Arias-Trejo \& Plunkett, submitted for publication). Furthermore, such effects may be impacted by the increase in the number of words known to children over the course of the second year of life, with Friedrich and Friederici (2005) reporting a significant correlation between a child's vocabulary size and the child's sensitivity to an association between an image and word by as early as 14-months of age.

Taken together, the results of previous research suggest a developing sensitivity to the similarity in phonological or semantic content of words over the first few years of life. Given the variability in children's sensitivity to phonological and semantic relationships between words at this age, the current study asks whether 2-year-olds show mediated priming effects, as has been demonstrated at older agegroups. We focus here on 2-year-olds because this is the earliest age when there is evidence for effects of phonological and semantic neighbourhoods on word recognition (Arias-Trejo \& Plunkett, 2010; Mani \& Plunkett, 2011). In addition, this would examine the development of mediated priming effects at a younger age than has been tested to-date (e.g., the 5-year-olds tested in Huang \& Snedeker, 2010). If 2-year-olds show sensitivity to phonological and semantic neighbourhoods in word recognition tasks, then one might reasonably expect to find similar effects of phono-semantically mediated priming at this age as has been shown later at 5-years of age. On the other hand, given the differential sensitivity to phonological neighbourhood size in 2-year-olds and older children (Coady \& Aslin, 2004; Storkel \& Hoover, 2012), one might expect to find reduced sensitivity to mediated priming effects at the younger age-group tested here.

Experiment 1 presents 2-year-olds with phono-semantically related prime-target pairs like boat-cup. Whilst boat and cup are not phonologically, semantically or visually related, boat is a cohort competitor of bowl, which is semantically and associatively related to cup. If word recognition involves cascaded activation of phono-semantically related words even at 2-years of age, we might expect infants to look longer at the picture of cup when primed by a phono-semantically related word like boat compared to an unrelated word, as in Yee and Sedivy (2006) and Huang and Snedeker (2010).

\section{Experiment 1}

\section{Method}

\section{Participants}

The participants were 28 infants at 24-months $(M=23.55 \mathrm{~m}$; Range $=23-25 \mathrm{~m})$. Nine additional infants were tested but were excluded due to experimenter error (6), due to their having hearing problems (1) or children not knowing most of the words presented to them according to parental communicative inventory reports (1) or providing enough data points per condition. Infants were recruited from the babylab database and came from homes where English was the only language in use.

\section{Procedure}

During the experiment, infants sat on their caregiver's lap in front of a projection screen. Cameras mounted directly above the pictures on the screen recorded infants' eye movements. Auditory stimuli were presented through a single loudspeaker located immediately behind the screen. Speech stimuli were produced by a female speaker of British English in an enthusiastic, child-directed manner.

Trials followed a similar pattern to Mani and Plunkett (2010, 2011). Each trial began with the presentation of an attention getter for $500 \mathrm{~ms}$, followed by a centrally located image of a familiar object (i.e., the prime image) on-screen for $1.5 \mathrm{~s}$ in silence. At the offset of the prime image, the screen stayed blank for $200 \mathrm{~ms}$, followed by the presentation of two images of familiar objects (i.e., target and distracter images) side-by-side for $2.5 \mathrm{~s}$. Fifty ms after the onset of these two images, infants were presented with a label for the target image in citation form. In half the trials (primed trials), the label for the target image (i.e., the heard label) was phono-semantically related to the unheard label for the prime image. For example, the prime boat is phonologically related to the sub-prime, bowl, which is semantically related to the target, cup. In related trials, the prime and sub-prime labels overlapped in the initial consonant and vowel (e.g., boat-bowl). Sub-primes and targets were associatively related (e.g., bowl-cup; Edinburgh Word Association Thesaurus and Birkbeck Word Association Norms) and were members of the same semantic category. We use the adult Edinburgh Word Association Thesaurus and the Birkbeck Word Association Norms as these are the only available norms for British English and have been used successfully to demonstrate semantic priming in children at the same age (Arias-Trejo \& Plunkett, 2010). In the other half of the trials (unrelated trials); the label for the target image (the heard label) was phonologically, semantically and phono-semantically unrelated to the label for the prime image. A total of eight prime-subprime-target triads were included in the final analysis (see Table 1 in the Appendix A for a list of these items).

Note that the prime image was never labelled. Exposure to a name-known image offers the infant an opportunity to generate a label for herself, as observed in infants and adults participating in visual world tasks (Meyer et al., 2007; Jescheniak, Schriefers, Garrett, \& Friederici, 2002, Huettig 
\& McQueen, 2007; Mani \& Plunkett, 2010). Allowing infants to generate the labels associated with the picture prime removes the constraint of having to label the prime image. This can be advantageous, since the rapid succession of presentation of prime and target labels can prove distracting for infants (Styles, Arias-Trejo, \& Plunkett, 2008).

Parents were asked to indicate whether their infants knew the words presented to them in the current experiment. According to average CDI scores, word-knowledge (including the words intended as sub-primes) was 87.79\%. Labels for the target, prime and distracter images were semantically and associatively unrelated (Edinburgh Word Association Thesaurus and Birkbeck Word Association Norms, Moss \& Older, 1996). The only attested relationship between targets and primes in primed trials was the phono-semantic relationship between the unheard prime label and the heard target label. There was no relationship between the primes and targets in unrelated trials. The distracter image was never labelled. Infants saw each image only once during the experiment. Target and distracter pairings were yoked and appeared in the primed and unrelated condition with equal frequency. Primes were counterbalanced, so the same prime image appeared in primed and unrelated trials equally. Targets appeared equally often to the left and to the right in primed and unrelated trials.

Speech stimuli were produced by a female speaker of British English in an enthusiastic, child-directed manner. Visual stimuli were computer images created from photographs, with one image for each word. The prime image appeared in the centre of the screen, while the target and distracter images appeared side-by-side on the screen.

\section{Scoring}

A digital-video scoring system assessed visual events on a frame-by-frame basis (every $40 \mathrm{~ms}$ ). This technique enabled blind coding of every eye fixation. As is standard in the infant eye-tracking literature, eye-movements launched between 233 to $2000 \mathrm{~ms}$ after the onset of the target word were analysed (Mani \& Plunkett, 2010, 2011; Swingley, Pinto, \& Fernald, 1999). This ensured that only those eye-movements that could reasonably be considered a response to the auditory stimulus were included in the analysis (see Swingley et al., 1999 for a detailed analysis of time-course of infants' fixations in the intermodal preferential looking task). Fixations that began earlier than $233 \mathrm{~ms}$ into the trial were recalculated from this timepoint. The coded video frames were used to determine the total amount of time infants looked at the target ( $\mathrm{T}$ ) and distracter (D) images. Based on the coded video frames, we calculated our dependent variable for analysis, i.e., the proportion of time $(\mathrm{T} /(\mathrm{T}+\mathrm{D}))$ infants spent looking at the target from $233 \mathrm{~ms}$ after target word onset, the Proportion of Target Looking measure (PTL).

\section{Results}

Fig. 1 plots the proportion of children's target looking throughout the duration of the trial in phono-semantically related trials compared to unrelated trials. According to Fig. 1, children look longer at the target in the phono-

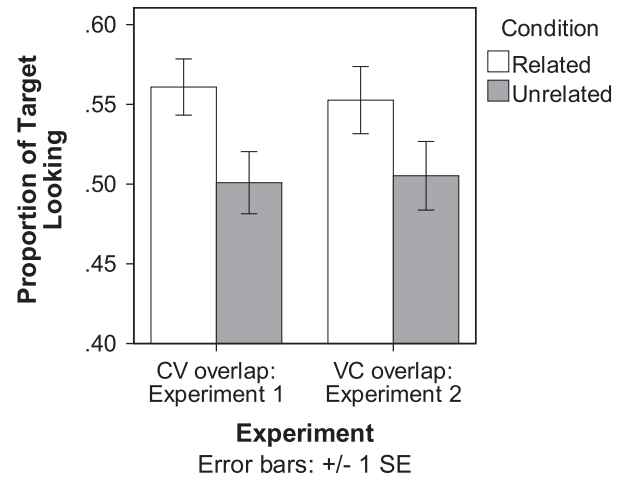

Fig. 1. Mean proportion of target looking in related and unrelated trials in Experiments 1 and 2 .

semantically related condition relative to the unrelated condition. To examine this pattern further, the proportion of children's target looking was analysed using a binomial logistic regression model (e.g., Baayen, Davidson, \& Bates, 2008) with condition (related, unrelated) as a fixed factor, as well as subjects and items as crossed random factors. Data points with residuals larger than 2 standard deviations from the mean were excluded as outliers. In addition, predictors such as frequency of the prime, target, or subprime in children's input at 24-months of age (Childfreq using CHILDES database: Bååth, 2010), children's knowledge of the items presented to them according to parental vocabulary estimates and the associative strength between the prime and the sub-prime were included in the model. None of these predictors improved the fit of the model ( $p s>.3$ ). However, log-likelihood of the model including condition as a fixed factor was significantly improved relative to the model excluding this factor $\left(\chi^{2}(1)=5.45\right.$; $p=.019)$. The results showed a significant effect of condition with $p$ values assessed using a Markov Chain Monte Carlo algorithm using 10,000 samples implemented using the pvals function from the $\mathrm{R}$ package languageR. As with the 5-year-olds tested in Huang and Snedeker (2010), 2year-olds in the current study looked longer at the target in related trials $(M=55 \%)$ compared to unrelated trials $(M=49 \%, t=-2.21: p-\mathrm{MCMC}=.02$; Mean Estimate $=-.06$; Upper bound $=-.006$; Lower bound $=-.11$ ).

\section{Discussion}

The current study set out to examine whether toddlers, like adults and 5-year-olds, show cascaded activation of phono-semantically related words during word recognition. We tested this by presenting children with primed and unrelated trials: in primed trials, the label for the prime image was phono-semantically related to the label for the target image. For instance, the prime boat shares the onset consonant and following vowel with the word bowl, which, in turn, is associatively related to the word cup, i.e., boat is phono-semantically related to cup. In unrelated trials, the label for the prime image was unrelated to the label for the target image. Children's target recognition showed a facilitatory effect of phono-semantic priming with increased target recognition in primed trials 
compared to unrelated trials. This provides evidence for cascaded activation of phono-semantically related words early in development, by 2-years of age.

Combining the results of previous experiments on children's sensitivity to phonological or semantic priming tasks, this appears to be the earliest age where one might reasonably expect children to display mediated priming. It is only by 24-months that children display robust neighbourhood effects in word-learning (Newman et al., 2009), as well as evidence for co-activation of phonologically related words in the form of inhibition (Mani \& Plunkett, 2011) or evidence for associative and/or semantic priming (Arias-Trejo \& Plunkett, submitted for publication; Styles \& Plunkett, 2011). Prior to this age, between 18- to 20months, while children display interference effects from a single "entrenched lexical competitor" in word learning tasks (Swingley \& Aslin, 2007) and pre-lexically driven facilitation effects from a phonologically related competitor in word recognition tasks (Mani \& Plunkett, 2010), there appears to be little evidence for co-activation of phonological or semantic neighbours (Arias-Trejo \& Plunkett, submitted for publication, Styles \& Plunkett, 2011) in word recognition earlier than 24-months of age.

The evidence available for co-activation of phonological neighbours even at 24-months of age can be interpreted in two ways. Consider the results of Mani and Plunkett (2011). In this task, children were presented with an overtly similar prime and target in related trials, e.g., ball (prime)-book (target). The evidence for co-activation of phonological neighbours in this task is that the degree of interference displayed in related trials was modulated by the size of shared cohort or neighbourhood of the prime and target - larger cohort/neighbourhood-greater interference, smaller cohort/neighbourhood-less interference. However, as Mani and Plunkett (2011) conclude, further analysis of the data suggests that the locus of these interference effects is the cohort/neighbourhood size of the target (across related and unrelated trials). Thus, while the influence of target's cohort is suggestive of co-activation of phonologically related words during word recognition, it does not constitute conclusive evidence.

An alternative explanation for the pattern of effects might be that the prime itself is the locus of modulated interference effects, rather than the prime cohort or target cohort (Dufour \& Peereman, 2003). For instance, primes from larger cohorts/neighbourhoods may be recognised more robustly than primes from smaller cohorts/neighbourhoods due to the greater position-specific frequency of the onset phonemes of primes from larger cohorts. Therefore, primes from larger cohorts may inhibit processing of the subsequently presented target more than primes from smaller cohorts, leading to the pattern of interference effects reported in Mani and Plunkett (2011). Moreover, subsequent presentation of a target overlapping in phonological features with the prime may further boost activation of the prime, given the overt overlap between target and prime labels (Marslen-Wilson \& Zwitserlood, 1989; Pitt \& Shoaf, 2002). This explanation holds the frequency of the phonemes of the prime label and the overt phonological overlap between prime and target responsible for the pattern of effects rather than the co-activation of the target's cohort.
More convincing evidence for the co-activation of phonological neighbours comes, therefore, from the results of Experiment 1 . Since we ensured that there was no overt overlap between the primes and the targets in the current experiment, Experiment 1 allows us to disentangle the effects of phonological overlap from the effects of lexical activation of cohort members (Marslen-Wilson \& Zwitserlood, 1989; Pitt \& Shoaf, 2002). That is, since prime and target share no overt phonological or semantic overlap in the current study, the finding of facilitation in recognition of phono-semantically related targets suggests that the prime activates onset overlapping neighbours to a sufficient extent for them to influence subsequent processing of the target. Furthermore, the opposing direction of effects in the current study (facilitation) and Mani and Plunkett (inhibition) rules out the inhibition-by-the-prime explanation of Mani and Plunkett (2011)'s results proposed above. Thus, the results of Experiment 1 corroborate Mani and Plunkett's claim for the co-activation of phonological neighbours in word recognition at 24-months of age.

Why does the current experiment find facilitation effects as opposed to the inhibitory priming effects reported by Mani and Plunkett (2011)? There are two main differences between the design of Mani and Plunkett (2011) and the current study that may explain the difference in the direction of effects obtained. First, the current study tests phono-semantic priming rather than phonological priming. However, embedding an additional layer in the relationship between prime and target should not change the direction of effects from inhibition to facilitation. If the relationship between the prime and sub-prime is inhibitory, then this should cascade through to the level of target recognition. Indeed, recent work examining phono-semantic priming with purely initial consonant overlap between prime and sub-prime report precisely such inhibitory effects (Huang, Khan, Wang, Geojo, \& Snedeker, 2011; Mani, 2010). Rather we suggest that the difference in the direction of effects might be explained by examining the phonological relationships between primes and subprimes across the studies. Mani and Plunkett (2011) presented children with onset-only overlap between prime and sub-prime, e.g., cat-cup, whilst the current study tested prime-sub-prime pairs with onset CV overlap (e.g., boat-bowl). Given the minimal overlap between cat and cup, a number of other words can compete for activation upon presentation of cat, e.g., car, cap, coat, etc., reducing the activation levels of cup. Indeed, Mani and Plunkett (2011) report that the size of the inhibition effects was modulated by the size of the activated cohort, with facilitation in recognition of words from small cohorts and interference in recognition of words from large cohorts. In the context of the current study, there are few other words that sound as similar to boat as bowl in the 24-month-old lexicon. The prime would, therefore, lead to greater activation of the sub-prime and cascaded activation of the target in the current study relative to Mani and Plunkett (2011).

Experiment 2 seeks to replicate the pattern of effects of Experiment 1 and examine this finding with regard to phonological overlap at a different position in the word, i.e., rhyme overlap, e.g., clock-sock. There are a number of reasons motivating separate examination of the effects of 
onset and rhyme overlap. On the one hand, the adult literature reports stronger and more consistent effects of rhyme priming relative to onset priming. Rhyme priming always elicits facilitation in target recognition, i.e., priming by clock speeds recognition of sock (Burton, 1992; Burton, Jongman, \& Sereno, 1993; Corina, 1992; Emmorey, 1989; Radeau, Morais, \& Dewier, 1989; Slowiaczek et al., 1987). In contrast, the direction and magnitude of effects with onset priming varies with the ISI between the prime and target, the task used (lexical decision versus shadowing tasks), the degree of phonological overlap between prime and target, the number of related and unrelated trials presented to participants in an experiment (Goldinger, Luce, Pisoni, \& Marcario, 1992; Pitt \& Shoaf, 2002; Radeau et al., 1989; Slowiaczek \& Pisoni, 1986; Slowiaczek et al., 1987). Furthermore, statistical analysis of the nature of phonological neighbourhoods reports that most phonological neighbours in English are rhyme- (e.g., hat/cat) rather than onset-overlapping (e.g., hat/ham; De Cara \& Goswami, 2002). Therefore, the results of Experiment 2 manipulating rhyme overlap might display clearer effects of phonosemantic priming relative to Experiment 1, thereby providing corroboratory evidence for the cascaded activation of phono-semantically related words.

On the other hand, it is often suggested that rhyme priming effects are typically pre-lexical (Radeau et al., 1989; Slowiaczek \& Hamburger, 1992). That is, these effects are typically driven by pre-activation of the phonemes shared by the prime and target label rather than by the pre-activation of the target itself. Evidence in favour of this hypothesis comes from findings that facilitation effects are also found with non-word primes (Cutler, Sebastián-Gallés, Soler-Vilageliu, \& van Ooijen, 2000; Dumay et al., 2001; Slowiaczek \& Hamburger, 1992) but only found when prime and target are both auditorally presented (Cutler et al., 2000; Dumay et al., 2001; Radeau et al., 1989). However, the fact that rhyme priming may be driven by pre-lexical processes does not preclude the possibility of rhyming words co-activating one another. Indeed, the high degree of phonological overlap between rhyming prime-target pairs may motivate subjects' responding (in the studies reviewed above) on the basis of pre-lexical phonological overlap alone, while nevertheless allowing lexical activation of the rhyming target. Examining mediated rhyme-priming provides, therefore, a more appropriate test of the lexicality of rhyme-priming: subjects' responding cannot be influenced by overt phonological overlap between the prime and the target, and any subsequent rhyme-priming can only be interpreted as being lexically driven. As in Experiment 1 , the only way for clock to influence recognition of an unrelated word such as shoe is through co-activation of the rhyming sub-prime sock.

\section{Experiment 2}

\section{Method}

\section{Participants}

The participants were 31 infants at 24-months $(M=24.6 \mathrm{~m}$; $\quad$ Range $=23.4-25.45 \mathrm{~m})$. Two additional infants were tested but were excluded due to fussiness (1) and experimenter error (1). Infants had no known hearing or visual problems and were recruited via the maternity ward at the local hospital. Infants came from homes where British English was the primary language in use.

\section{Procedure}

The experimental set-up was similar to Experiment 1 . The only difference was that rather than using a fixed attention-getter between each trial, infants were directed to look at the screen through a variable attention-getter in the form of a pleasant chime and a cross being presented to infants at the start of each trial. Otherwise, trials followed the same pattern as in Experiment 1. Experiment 2 presented infants with eight trials, each consisting of a prime image presented in silence, followed by two test images and a spoken word that matched one of those test images. In half the trials (primed trials), the label for the target image (i.e., the heard label) was phono-semantically related to the unheard label for the prime image (see Table 2 in the Appendix A for a list of items). For example, the prime clock rhymes with the sub-prime, sock, which is semantically related to the target label, shoe. Therefore, in related trials, the prime and sub-prime labels rhymed with each other (e.g., clock-sock), whilst sub-primes and targets were associatively related (e.g., sock-shoe; Edinburgh Word Association Thesaurus and Birkbeck Word Association Norms) and were, in addition, members of the same semantic category. In the other half of the trials (unrelated trials), the label for the target image (the heard label) was phonologically, semantically and phono-semantically unrelated to the label for the prime image.

According to CDI scores collected from the infants who took part in Experiment 2, the average word-knowledge of the words used in Experiment 2 was 92\% (including the intended sub-prime). Labels for the target, prime and distracter images were semantically and associatively unrelated (Edinburgh Word Association Thesaurus and Birkbeck Word Association Norms, Moss \& Older, 1996). The only attested relationship between targets and primes in primed trials was the phono-semantic relationship between the unheard prime label and the heard target label. There was no relationship between the primes and targets in unrelated trials. The distracter image was never labelled. Order and mode of presentation of the trials were similar to Experiment 1. As in Experiment 1, results are reported using the PTL measure.

\section{Results}

Fig. 1 plots the proportion of children's target looking throughout the duration of the trial in phono-semantically related trials compared to unrelated trials. As in Experiment 1 , the data plotted in Fig. 1 suggests that infants looked significantly longer at the target in phono-semantically related trials compared to unrelated trials. To examine this pattern further, the proportion of children's target looking was analysed using a binomial logistic regression model (e.g., Baayen et al., 2008) with condition (related, unrelated) as a fixed factor, as well as subjects and items as crossed random factors. As in Experiment 1, data 
points with residuals more than two standard deviations from the mean were excluded from the analysis. In addition, predictors such as frequency of the prime, target, or sub-prime in children's input at 24-months of age (Childfreq using CHILDES database: Bååth, 2010), children's knowledge of the items presented to them according to parental vocabulary estimates and the associative strength between the prime and the sub-prime were included in the model. None of these predictors significantly improved the fit of the model ( $p s>.2$ ). However, log-likelihood of the model including condition as a fixed factor was significantly improved relative to the model excluding this factor $\left(\chi^{2}(1)=4.26 ; p=.03\right)$. The results showed a significant effect of condition with $p$ values assessed using a Markov Chain Monte Carlo algorithm using 10,000 samples implemented using the pvals function from the R package languageR. As with the 5-year-olds tested in Huang and Snedeker (2010), 2-year-olds in the current study looked longer at the target in related trials $(M=55 \%)$ compared to unrelated trials $(M=51 \%, t=-2.09 ; p$-MCMC $=.04$; Mean Estimate $=-.06$; Upper bound $=-.003$; Lower bound $=-.12$ ).

We also combined the data from Experiments 1 and 2 to examine whether there was a difference in the priming effects across the two experiments. This would examine whether position of overlap impacted the strength of effects as suggested by some models of word processing (Marslen-Wilson \& Welsh, 1978; Marslen-Wilson \& Zwitserlood, 1989). However, adding position of overlap as a predictor did not improve the fit of the model $(p>.8)$. Neither was there a main effect of position of overlap or interactions between condition (unrelated, related) and position of overlap ( $p s=.9$ ).

\section{Discussion}

Experiment 2 had two main goals. First, to examine whether we could replicate the pattern of results found with mediated onset priming in Experiment 1 and provide further evidence for cascaded activation of phono-semantically related words at 2-years of age. Second, to examine the lexicality of rhyme-priming effects - in other words, does activation of a word like clock lead to lexical-level activation of its rhyme-partner sock? Indeed, as in Experiment 1 , we found improved recognition of the target in phono-semantically related trials compared to unrelated trials. As mentioned in the Discussion of the results of Experiment 1, the only way to explain the influence of a word like clock on recognition of shoe is through co-activation of phonologically related words like sock. That is, since prime and target share no overt phonological or semantic overlap in the current study, the finding of facilitation in recognition of phono-semantically related targets suggests that the prime activates onset-(Experiment 1) and rhymeoverlapping (Experiment 2) neighbours to a sufficient extent for them to influence subsequent processing of the target.

Previous results with rhyme-priming in the adult literature suggest that rhyme-priming is a predominantly pre-lexical effect (Radeau et al., 1989; Slowiaczek \& Hamburger, 1992), without however precluding the possibility that a prime can activate a rhyming target. Whether or not the rhyme-priming effect reported in the literature is pre-lexical in nature can be appropriately tested in the mediated rhyme-priming task used here. Thus, while previous rhyme priming effects may hinge purely on pre-lexical activation of the phonemes shared by the overtly similar primes and targets, e.g., clock-sock, the current results provide evidence for lexical-level activation of the sub-prime sock leading to facilitated recognition of the target shoe.

We did not, however, find greater effects of priming in Experiment 2 relative to Experiment 1. This might have been expected by the greater consistency of rhyme priming effects (in contrast to onset priming) in the adult literature (Burton, 1992; Burton et al., 1993; Corina, 1992; Emmorey, 1989; Radeau et al., 1989; Slowiaczek et al., 1987). Perhaps the mediated nature of the priming effects in the current experiment reduced any advantage to be gained from rhyme priming with regard to onset priming. Or perhaps the paradigm and the young population tested here do not allow for examining subtle graded effects in word recognition. Nevertheless, the results of Experiment 2 extend the results of Experiment 1 to mediated rhyme priming while providing further evidence for the cascaded activation of phono-semantically related words at 24months of age. In what follows, we discuss the implications of these two experiments for our understanding of the processes driving word recognition by infants and adults.

\section{General discussion}

The current experiments add to the considerable literature on the processes underlying word recognition in infants and adults by providing evidence for cascaded activation of phono-semantically related words in word recognition by 2-year-old infants. This is earlier than similar results on cascaded activation of phono-semantically related words by 5-year-olds (Huang \& Snedeker, 2010) and adults (Marslen-Wilson \& Zwitserlood, 1989; Yee \& Sedivy, 2006). The similarity in the pattern of results strongly supports the conclusion that word recognition, even in 2year-olds, involves further processing of not just phonologically and semantically related words, but also cascaded activation of phono-semantically related words, i.e., of words phonologically and semantically related to these already activated words.

We have suggested that this is the earliest possible age where one might expect to find evidence for mediated priming, since there is little evidence for co-activation of phonological or semantic neighbours prior to this age in the published literature. Thus the results of the current study might capture the beginnings of cascaded activation of related words as seen in adults and older children, which is nevertheless susceptible to increasing vocabulary size in the latter populations (Coady \& Aslin, 2004; Storkel \& Hoover, 2012).

While this suggests a surprising degree of cascaded processing during speech perception in the 2-year-old cognitive system, the straightforward explanation for this finding is that the additional load of processing phono- 
semantically related words might be outweighed by the benefits of pre-activating words that might subsequently be called into use. For instance, having heard the syllable/ka/, pre-activating words consistent with this onset speeds processing of these words relative to words inconsistent with this onset and leads to faster recognition of the intended word, e.g., cat. Furthermore, activating the semantic associates of words would, in keeping with standard explanations of semantic priming (Meyer \& Schvaneveldt, 1971), improve the speed of processing of these words that may also later be called into use, e.g., dog, hat, coat, etc. Such an explanation is easily captured by models of speech processing, e.g., the TRACE model of word recognition (McClelland \& Elman, 1986). While TRACE does not allow for semantically mediated effects in word recognition as yet, the phonological aspect of these results is neatly incorporated into the model. Indeed, the results of Mani and Plunkett $(2010,2011)$ suggesting the onset of lexical-level co-activation of phonologically related words at 24-months of age has recently been replicated by a TRACE simulation of the data (Mayor, 2011). The architecture of TRACE implies that activation from the phoneme level feeds through to simultaneously activated words at the lexical level sharing the activated phonemes. This would necessitate that activation of the word boat lends activation to other words that sound similar to this word (overlapping at the phonemic level), e.g., bowl, coat. While within-level inhibitory connections might suppress the activation of these words to an extent, these words are nevertheless sufficiently activated and may lead (outside of TRACE) to cascaded activation of words semantically related to bowl or coat. This explanation assumes that the phonologically and phono-semantically related lexical items are regularly activated during processing such that words that may be relevant to a particular discourse and be called into use subsequently are pre-activated.

There are, nevertheless, a few caveats to this claim that suggest multiple new avenues of research. First, we note that it is not necessary to assume that the phono-semantically related lexical items are activated during processing. An alternative explanation for the results hinges on the assumption that the lexicon is coded in terms of semantic features (Cree \& McRae, 2003; McRae \& Boisvert, 1998). Therefore, hearing the syllable/ka/activates the word cat, whose semantic features overlap closely with the semantic features of the word $d o g$, thereby making it easier for $d o g$ to be recognised. Thus, while the lexical item dog may not be activated, activation of the semantic representations of the activated phonologically related words would be adequate to explain the pattern of results obtained. Indeed, a similar explanation holds for previous experiments examining semantic priming in toddlers. Facilitated recognition in semantically related trials need not necessarily imply activation of the semantically related lexical items but rather activation of the semantic features shared by primes and targets. Analogous to the current set of studies, then, it would be interesting to see whether similar results are obtained using phono-semantic priming where the target (e.g., cap) is phonologically related to a semantic competitor (e.g., cat) of the prime (e.g., dog). This would provide more compelling evidence for lexical-level activa- tion of semantic competitors in word recognition than semantic priming tasks to-date.

However, while explanation of the results may be ambiguous between activation of the semantic features of the sub-prime (footwear, etc.) or the semantic associates of the sub-prime (shoe, foot, etc.), there is little such ambiguity regarding the activation of the phonologically related sub-prime. The current results, therefore, provide strong evidence for the activation of phonologically related words during word recognition by 2-year-olds. Indeed, as Marslen-Wilson and Zwitserlood (1989) suggest using a similar task, the current results provide clearer evidence for activation of phonologically related words than previous phonological priming experiments with toddlers (Mani \& Plunkett, 2011), due to our avoiding of direct phonological overlap between the prime and target in the current study. Any influence of the prime on target recognition, therefore, cannot be attributed to phonological level overlap alone and must necessarily be caused by lexical activation of the phonologically related sub-prime, and cascaded processing of its semantic associates.

The results of Experiment 2 also add to the literature on phonological effects in word recognition. As suggested above, the most straightforward explanation for the influence of a word like clock on recognition of shoe, is through mediated priming by the rhyme competitor, sock. This would suggest that rhyme and onset competitors are routinely activated in word recognition, which appears to contradict results in the adult literature suggesting a prelexical basis for rhyme-priming effects. However, we suggest that co-activation of rhyme competitors need not exclude a predominantly pre-lexical basis for rhyme priming. Furthermore, akin to Newman et al. (2009) and Mani and Plunkett (2011), effects of mediated priming may be modulated by the number of similar sounding words in the lexicon. This would be in keeping with studies examining neighbourhood effects in word recognition showing that words from dense neighbourhoods are recognised more slowly than words from sparse neighbourhoods (Goldinger et al., 1989; Luce \& Pisoni, 1998; Vitevitch \& Luce, 1998).

We note, however, that the neighbours lead to reduced recognition of an intended target only in word recognition studies but not in word production studies. The majority of word production studies to-date typically report greater accuracy and efficiency in the production of targets with more neighbours than targets with fewer neighbours (Gordon, 2000, 2002; Vitevitch, 1997, 2002). This dichotomy between neighbourhood effects in word production and word recognition has recently come under much scrutiny and is pertinent to explaining the effects found in the current study.

The relevance of this dichotomy to the current study stems from the nature of the task presented to children. As in Mani and Plunkett (2010), the prime image was always presented in silence. Nevertheless, we found a robust influence of the relationship between the un-presented prime label and the target image in both Experiments 1 and 2 . This influence can only be explained by suggesting that infants, like adults (Meyer et al., 2007), internally generate the label of a name-known image in such tasks. The current study, therefore, supports the finding of Mani and 
Plunkett (2010) that infants internally generate the labels of name-known images.

Such a finding does, however, move discussion of the current results from the realm of word recognition to word production, albeit implicit word production. Assuming that implicit generation involves production-based processes, the results of the current study provide evidence for the co-activation of phonological competitors in word production. What implications do the current results have, then, for models of word production? There are three main kinds of word production models, which mainly differ on the extent to which semantic access of a meaning representation (lemma) is separated from phonological encoding of the word form representation. Discrete-stage models of word production argue that lemma access is completed before phonological encoding can begin - thus only the chosen lemma will be phonologically encoded (Levelt, Roelofs, \& Meyer, 1999). Cascaded theories of word production suggest that lemmas are phonologically encoded before any one lemma can be uniquely identified as the target. Thus semantic competitors of the prime would also be phonologically encoded (Caramazza, 1997; Humphreys, Riddoch, \& Quinlan, 1988). Finally, interactive theories not only allow for semantic competitors to be simultaneously encoded phonologically, but also allow for phonological representations to influence activation at the lemma level (Dell, Schwartz, Martin, Saffran, \& Gagnon, 1997; Harley, 1993) - thus activating and encoding not just semantic competitors but also phonological competitors. Such flexibility in interactive models allows the phonological and semantic levels to feed back to each other, allowing cascaded activation of phonological and semantic competitors at all levels of representation. Thus, interactive models of word production appear to best allow for the mediated priming effects described in the current study. ${ }^{1}$ However, to the extent that our experiments were not designed to distinguish between different models of speech production, any discussion regarding the production-based mechanisms at work in the current study is purely speculative. It would be interesting for future research to examine the interaction between perception- and production-based models of word recognition especially in the context of visual priming tasks such as those used in the current study.

The two experiments presented here do, however, provide strong evidence of cascaded processing in toddler word recognition: Word recognition involves the simultaneous activation of alternative potential word candidates with phonological, semantic and phono-semantic overlap to the speech token requiring recognition or the semantic token requiring phonological encoding. In most cases, the influence of these competing candidates may be reduced once the target is uniquely identified. However, our tasks appear to sustain the activation of these other words long enough for us to measure their influence on processing.

\section{Acknowledgments}

This work was funded by the German Initiative for Excellence - Institutional Strategy (Experiment 1 and write-up) and The British Academy (Experiment 2).

\section{Appendix}

See Tables 1 and 2 .

Table 1

Stimuli in Experiment 1. Note that the sub-prime is never presented to

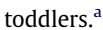

\begin{tabular}{|c|c|c|c|}
\hline \multirow[t]{2}{*}{ Prime } & \multirow[t]{2}{*}{ Intended sub-prime } & \multicolumn{2}{|l|}{ Target } \\
\hline & & Related & Unrelated \\
\hline Boat & Bowl & Cup & Shirt \\
\hline Cheese & Cheek & Nose & Dress \\
\hline Plane & Plate & Spoon & Ball \\
\hline Mouse & Mouth & Tooth & Cup \\
\hline Hat & Hand & Foot & Butter \\
\hline Cat & Catch & Ball & Spoon \\
\hline Bin & Bib & Shirt & Nose \\
\hline Comb & Coat & Dress & Tooth \\
\hline Toe $^{a}$ & Toast & Butter & Girl \\
\hline $\operatorname{Dog}^{\mathrm{a}}$ & Doll & Girl & Foot \\
\hline
\end{tabular}

a The data from one item (dog (prime)-doll (sub-prime)-girl (target)) was excluded from the analysis because these sub-prime, doll, is pronounced differently to $d o g$ in the South-Eastern British accent of the children tested, i.e., the prime is produced with a monophthong [0] and the sub-prime with a diphthong, [or]. The data from a second triad (ToeToast-Butter) was excluded from the analysis due to the proportion of target looking for this item falling outside the normal range of variance (more than 2.5 SD from the mean), with subjects taking longest to respond to this item (Mean $\mathrm{PTL}=33 \%$ ) relative to the other items $(M=53 \%, S D=.06)$. We suggest this is because this was the only disyllabic target in the experiment.

Table 2

Stimuli in Experiment 2. Note that the sub-prime is never presented to toddlers. ${ }^{\text {a }}$

\begin{tabular}{|c|c|c|c|}
\hline \multirow[t]{2}{*}{ Prime } & \multirow[t]{2}{*}{ Intended sub-prime } & \multicolumn{2}{|l|}{ Target } \\
\hline & & Related & Unrelated \\
\hline Clock & Sock & Shoe & Door \\
\hline Frog $^{\mathrm{a}}$ & Dog & Cat & Hat \\
\hline Boat & Coat & Hat & Table \\
\hline Bear $^{\mathrm{a}}$ & Chair & Table & Shoe \\
\hline Tree & Key & Door & Fork \\
\hline Duck & Truck & Car & Cot \\
\hline Moon & Spoon & Fork & Cat \\
\hline Head & Bed & Cot & Car \\
\hline
\end{tabular}

a One of the triads was excluded from the analysis due to the prime and target belonging to the same taxonomic category, i.e., the prime frog (subprime dog) and the target cat. Similarly, as in Experiment 1, the data from one triad (bear-chair-table) was excluded since this item included the only disyllabic target across the experiment.

\footnotetext{
1 Discrete-stage theories of word production do allow for an influence of phonological neighbours on word production through internal monitoring of the production system by the comprehension system. However, as noted by Dell and Gordon (2003), it is difficult to see how the comprehension system could aid production of targets with many neighbours while also hindering recognition of targets with many neighbours.
}

\section{References}

Arias-Trejo, N., \& Plunkett, K. (2010). Lexical semantic priming effects during infancy. Philosophical Transactions of the Royal Society B, 364, 3633-3647. 
Arias-Trejo, N., \& Plunkett, K. (submitted for publication). What's in a link? Associative and semantic priming effects in late infancy.

Bååth, R. (2010). ChildFreq: An online tool to explore word frequencies in child language. LUCS Minor, 16, 1-6.

Baayen, R. H., Davidson, D. J., \& Bates, D. M. (2008). Mixed-effects modeling with crossed random effects for subjects and items. Journal of Memory and Language, 59, 390-412.

Burton, M. W. (1992). Syllable priming in auditory word recognition. In Poster session presented at the 33rd annual meeting of the psychonomic society, St. Louis, MO.

Burton, M. W., Jongman, A., \& Sereno, J. (1993). Phonological and orthographic priming effect in auditory and visual word recognition. In Poster session presented at the 34th annual meeting of the psychonomic society, Washington, DC.

Caramazza, A. (1997). How many levels of processing are there in lexical access? Cognitive Neuropsychology, 14, 177-208.

Charles-Luce, J., \& Luce, P. A. (1990). Similarity neighborhoods of words in young children's lexicons. Journal of Child Language, 17, 205-215.

Coady, J. A., \& Aslin, R. N. (2004). Young children's sensitivity to probabilistic phonotactics in the developing lexicon. Journal of Experimental Child Psychology, 89, 183-213.

Corina, D. P. (1992). Syllable priming and lexical representations: Evidence from experiments and simulations. In D. P. Corina (Ed.) Proceedings of the 16th annual conference of the cognitive science society (pp. 779-784).

Cree, G. S., \& McRae, K. (2003). Analyzing the factors underlying the structure and computation of the meaning of chipmunk, cherry, chisel, cheese and cello (and many other such concrete nouns). Journal of Experimental Psychology: General, 132, 163-201.

Cutler, A., Sebastián-Gallés, N., Soler-Vilageliu, O., \& van Ooijen, B. (2000) Constraints of vowels and consonants on lexical selection: Crosslinguistic comparisons. Memory \& Cognition, 28, 746-755.

De Cara, B., \& Goswami, U. (2002). Similarity relations among spoken words: The special status of rimes in English. Behavior Research Methods, Instruments, and Computers, 34, 416-423.

Dell, G. S., \& Gordon, J. K. (2003). Neighbors in the lexicon: Friends or foes? In N. O. Schiller \& A. S. Meyer (Eds.), Phonetics and phonology in language comprehension and production: Differences and similarities. New York: Mouton.

Dell, G. S., Schwartz, M. F., Martin, N., Saffran, E. M., \& Gagnon, D. A. (1997). Lexical access in aphasic and nonaphasic speakers. Psychological Review, 104, 801-838.

Dufour, S., \& Peereman, R. (2003). Inhibitory priming effects in auditory word recognition: When the target's competitors conflict with the prime word. Cognition, 88, B33-B44.

Dumay, N., Benraïss, A., Barriol, B., Colin, C., Radeau, M., \& Besson, M. (2001). Behavioral and electrophysiological study of phonological priming between bisyllabic spoken words. Journal of Cognitive Neuroscience, 13, 121-143.

Emmorey, K. D. (1989). Auditory morphological priming in the lexicon. Language and Cognitive Processes, 4, 73-92.

Friedrich, M., \& Friederici, A. D. (2005). Lexical priming and semantic integration reflected in the event-related potential of 14-month-olds. NeuroReport, 16, 653-656.

Goldinger, S. D., Luce, P. A., \& Pisoni, D. B. (1989). Priming lexical neighbours of spoken words: Effects of competition and inhibition. Journal of Memory and Language, 28, 501-518.

Goldinger, S. D., Luce, P. A., Pisoni, D. B., \& Marcario, J. K. (1992). Formbased priming in spoken word recognition - The roles of competition and bias. Journal of Experimental Psychology: Learning, Memory and Cognition, 18, 1211-1238.

Gordon, J. K. (2000). Aphasic speech errors: Spontaneous and elicited contexts. Montreal, Quebec: McGill University.

Gordon, J. K. (2002). Phonological neighborhood effects in aphasic speech errors: Spontaneous and structured contexts. Brain and Language.

Harley, T. A. (1993). Connectionist approaches to language disorders. Aphasiology, 7, 221-249.

Huang, Y. -T., Khan, M., Wang, S., Geojo, A., \& Snedeker, J. (2011). From sounds to concepts and back again: Cascaded processing during object and word recognition. In Paper presented at the biannual meeting of the society for research in child development, Montreal, Canada.

Huang, Y.-T., \& Snedeker, J. (2010). Cascading activation across levels of representation in children's lexical processing. Journal of Child Language, 26, 1-18.

Huettig, F., \& McQueen, J. M. (2007). The tug-of-war between phonological, semantic, and shape information in languagemediated visual search. Journal of Memory and Language, 57, 460-482.
Huettig, F., Singh, N., \& Mishra, R. K. (2011). Language-mediated visual orienting behavior in low and high literates. Frontiers in Psychology, 2, 285. http://dx.doi.org/10.3389/fpsyg.2011.00285.

Humphreys, G. W., Riddoch, J. M., \& Quinlan, P. T. (1988). Cascade processes in picture identification. Cognitive Neuropsychology, 5(1), 67-104.

Jescheniak, J. D., \& Levelt, W. J. M. (1994). Word frequency effects in speech production: Retrieval of syntactic information and of phonological form. Journal of Experimental Psychology: Learning, Memory, and Cognition, 20, 824-843.

Jescheniak, J. D., Schriefers, H., Garrett, M. F., \& Friederici, A. D. (2002). Exploring the activation of semantic and phonological codes during speech planning with event-related brain potentials. Journal of Cognitive Neuroscience, 14, 951-964.

Levelt, J. M. W., Roelofs, A., \& Meyer, A. S. (1999). A theory of lexical access in speech production. Behavioural and Brain Sciences, 22, 1-75.

Luce, P. A., \& Pisoni, D. B. (1998). Recognizing spoken words: The neighborhood activation model. Ear and Hearing, 19-36.

Mani, N. (2010). When cup primes dog: Phono-semantic priming in the toddler lexicon. In Proceedings of the 34th annual Boston University conference on language development (pp. 291-302). Boston: Cascadilla Press.

Mani, N., \& Plunkett, K. (2010). In the infant's mind's ear: Evidence for implicit naming. Psychological Science, 21, 908-913.

Mani, N., \& Plunkett, K. (2011). Phonological priming and cohort effects in toddlers. Cognition, 121, 196-206.

Marslen-Wilson, W. D., \& Welsh, A. (1978). Processing interactions during word-recognition in continuous speech. Cognitive Psychology, 10, 29-63.

Marslen-Wilson, W. D., \& Zwitserlood, P. (1989). Accessing spoken word: The importance of word onsets. Journal of Experimental Psychology: Human Perception and Performance, 15, 576-585.

Mayor, J. (2011). The emergence of lexical networks: Insights from TRACE simulations. In Presentation at the 17th Meeting of the European Society for Cognitive Psychology, San Sebastian, Spain.

McClelland, J. L., \& Elman, J. L. (1986). The TRACE model of speech perception. Cognitive Psychology, 18, 1-86.

McRae, K., \& Boisvert, S. (1998). Automatic semantic similarity priming. Journal of Experimental Psychology: Learning, Memory and Cognition, 24, 558-572.

Metsala, J. L., \& Walley, A. C. (1998). Spoken vocabulary growth and the segmental restructuring of lexical representations: Precursors to phonemic awareness and early reading ability. In J. L. Metsala \& L. C. Ehri (Eds.), Word recognition in beginning literacy (pp. 89-120). Hillsdale, NJ: Erlbaum.

Meyer, A. S., Belke, E., Telling, A., \& Humphreys, G. W. (2007). Early activation of object names in visual search. Psychonomic Bulletin $\mathcal{E}$ Review, 14, 710-716.

Meyer, D. E., \& Schvaneveldt, R. W. (1971). Facilitation in recognizing pairs of words: Evidence of dependence between retrieval operations. Journal of Experimental Psychology, 90, 227-234.

Moss, H., \& Older, L. (1996). Birkbeck word association norms. Associated Press.

Newman, R., Samuelson, L., \& Gupta, P. (2009). Learning novel neighbours: Distributed mappings help children and connectionist models. In Proceedings of the 30th annual meeting of the cognitive science society (pp. 29-34).

Pitt, M. A., \& Shoaf, L. (2002). Revisiting bias effects in word-initial phonological priming. Journal of Experimental Psychology: Human Perception and Performance, 28, 1120-1130.

Radeau, M., Morais, J., \& Dewier, A. (1989). Phonological priming in spoken word recognition: Task effects. Memory $\mathcal{E}$ Cognition, 17, 525-535.

Slowiaczek, L. M., \& Hamburger (1992). Prelexical facilitation and lexical interference in auditory word recognition. Journal of Experimental Psychology: Learning, Memory and Cognition, 18, 1239-1250.

Slowiaczek, L. M., Nusbaum, H. C., \& Pisoni, D. B. (1987). Phonological priming in auditory word recognition. Journal of Experimental Psychology: Learning, Memory and Cognition, 13, 64-75.

Slowiaczek, L. M., \& Pisoni, D. B. (1986). Effects of phonological similarity on priming in auditory lexical decision. Memory $\mathcal{E}$ Cognition, 14, 230-237.

Storkel, H. L., \& Hoover, J. R. (2012). The influence of part-word phonotactic probability/neighbourhood density on word learning by pre-school children varying in expressive vocabulary. Journal of Child Language. http://dx.doi.org/10.1017/S0304000910000176.

Styles, S. J., Arias-Trejo, N., \& Plunkett, K. (2008). Priming and lexical interference in infancy. In Proceedings of the annual meeting of the cognitive science society, Washington, DC. 
Styles, S. J., \& Plunkett, K. (2011). Early links in the early lexicon. In G. Gaskell \& P. Zwitzerlood (Eds.), Lexical representation: A multidisciplinary approach (pp. 51-88). Berlin: Mouton de Gruyter.

Swingley, D., \& Aslin, R. N. (2000). Spoken word recognition and lexical representation in very young children. Cognition, 76, 147-166.

Swingley, D., \& Aslin, R. N. (2002). Lexical neighborhoods and the word form representations of 14-month-olds. Psychological Science, 13, 480-484.

Swingley, D., \& Aslin, R. N. (2007). Lexical competition in young children's word learning. Cognitive Psychology, 54, 99-132.

Swingley, D., Pinto, J., \& Fernald, A. (1999). Continuous processing in word recognition at 24-months. Cognition, 71, 73-108.

Torkildsen, J. V. K., Sannerud, T., Syversen, G., Thormodsen, R., Simonsen, H. G., Moen, I., et al. (2006). Semantic organization of basic level words in 20-month-olds: An ERP study. Journal of Neurolinguistics, 19, 431-454.
Vitevitch, M. S. (1997). The neighborhood characteristics of malapropisms. Language and Speech, 40, 211-288.

Vitevitch, M. S. (2002). The influence of phonological similarity neighborhoods on speech production. Journal of Experimental Psychology: Learning, Memory, and Cognition, 28, 735-747.

Vitevitch, M. S., \& Luce, P. A. (1998). When words compete: Levels of processing in perception of spoken words. Psychological Science, 9, 325-329.

White, K. S., \& Morgan, J. L. (2008). Subsegmental detail in infants' early lexical representations. Journal of Memory and Language, 59, 114-132.

Yee, E., \& Sedivy, J. (2006). Eye movements to pictures reveal transient semantic activation during spoken word recognition. Journal of Experimental Psychology: Learning, Memory, and Cognition, 32, 1-14.

Ziegler, J. C., \& Goswami, U. C. (2005). Reading acquisition, developmenta dyslexia and skilled reading across languages: A psycholinguistic grain size theory. Psychological Bulletin, 131, 3-29. 